\title{
Frequency-dependent fertilisation involving rye B chromosomes
}

\author{
M. J. Puertas, \\ J. M. Vega, \\ F. Romera and \\ M. Diez
}

\author{
Departamento de Genética, Facultad de Biología,
} Universidad Complutense, 28040 Madrid, Spain.

The transmission of B chromosomes in rye was studied using both an isozyme locus (Got-3) and B chromosomes as markers of the gametes involved in fertilisation. Four experimental populations were established in which male parents carried 0 or $2 \mathrm{Bs}$ at different frequencies and were homozygous or heterozygous for Got-3. Female parents carried $0 \mathrm{~B}$ or $2 B$ and were all homozygous. The origin of the pollen types involved in fertilisation was recognized in the descendants by determining their B number and their Got-3 phenotype. The data showed firstly, that pollen produced by $0 B$ or $2 B$ males did not fertilise at random when these males were present at different frequencies. Secondly, that pollen from $2 \mathrm{~B}$ plants was preferentially involved in fertilisation when the proportion of plants carrying $2 \mathrm{~B}$ was low and, conversely, pollen from $0 \mathrm{~B}$ plants was preferentially involved in fertilisation when the proportion of $2 \mathrm{~B}$ plants was high. The selfish nature of $B$ chromosomes is discussed.

\section{INTRODUCTION}

The non-Mendelian mode of transmission of rye B chromosomes is well known at the cytological level, with Bs undergoing directed non-disjunction to the nucleus giving rise to the gametes (Müntzing, 1946; Håkanson, 1948). The processes result in the accumulation of Bs in a proportion of the gametes, and this accumulation is compensated for by the low fitness of plants carrying a high number of Bs (Müntzing, 1963; Puertas et al., 1985).

The mode of transmission of Bs at the population level, however is still not completely understood. In a recent paper (Puertas et al., 1986) we proposed that B chromosome behaviour is selfishlike, since the advantage of gametes carrying Bs seemed to be of benefit only to the B chromosomes themselves. The advantage or disadvantage of gametes carrying Bs depended on the frequency of B chromosomes in the population. Pollen carrying B chromosomes became relatively more advantageous when its frequency declined. Therefore, we proposed that frequency-dependent selection occurs to maintain the B chromosome polymorphism in rye.

Rye plants with Bs produce male and female gametes with and without Bs at different frequencies. Thus, it is usually impossible to determine whether a $0 \mathrm{~B}$ plant is descendant from a $0 \mathrm{~B} \times 0 \mathrm{~B}$, $0 \mathrm{~B} \times \mathrm{B}$ or $\mathrm{B} \times \mathrm{B}$ cross. In the present work we have used an isozyme locus (Got-3) as a marker of the gametes involved in fertilisation, in order to determine the differential fertilisation of gametes with or without B chromosomes, depending on the frequency of $\mathrm{Bs}$ in the population.

\section{MATERIAL AND METHODS}

Secale cereale of the variety JNK was used. This variety naturally carries $\mathrm{B}$ chromosomes.

The seeds were first germinated on moist filter paper and the chromosome number of each plant was then established in the root tips. Roots were fixed in $1: 3$ acetic alcohol and then stained by the Feulgen method.

When these plants reached a convenient stage of development a sample of their leaves was analyzed by protein electrophoresis to determine their phenotypes for glutamate oxaloacetate transaminase (GOT). In particular, we have studied the GOT-3 isozyme. This is a dimeric enzyme controlled by a single locus ( Got-3) with two alleles (Pérez de la Vega and Allard, 1984), so that, three isozyme phenotypes can be detected: 11,12 and 22 . In the following, numbers in italics will refer to alleles or phenotypes for Got-3. 
Electrophoresis was carried out using crude leaf extracts absorbed in paper wicks (Whatman No. $3,0 \cdot 2 \times 0.5 \mathrm{~cm}$ ) and inserted in 8 per cent horizontal polyacrylamide gels. Tris-citric acid, $p \mathrm{H} 7 \cdot 75$ was the gel buffer, and $\mathrm{NaOH}$-boric acid was the electrode buffer. The staining procedure was that described by Decker and Rau (1963), with minor modifications.

After determining the $\mathrm{B}$ chromosome number and the Got-3 phenotype of each individual plant, the appropriate plants were transplanted in an experimental field and arranged in four plots, as given in table 1.

Rye has hermaphroditic flowers and is mainly cross-pollinating. To be certain that no self-pollination occurred within plots, however, the spikes of plants that were used as females were emasculated. Nothing was done to plants used as males, and in the following, we shall name emasculated plants "females" and non-emasculated plants "males".

In all plots (i) the males were sown in the centre of the plot with the females surrounding them, (ii) plants with different numbers of $\mathrm{B}$ chromosomes and GOT phenotypes were sown at random within each plot, (iii) at the time of anthesis each plot was covered with a thin white cotton fabric to allow free pollination within each plot, and to prevent pollination among plots, so that pollen was potentially able to fertilise at random all the females within a given plot, (iv) offspring were collected individually from females only, (v) the

Table 1 Composition of the plots

\begin{tabular}{|c|c|c|c|c|c|}
\hline \multicolumn{2}{|c|}{ Plot } & \multirow{2}{*}{$\begin{array}{l}\begin{array}{l}\text { No. } \\
\text { plants }\end{array} \\
5 \\
5\end{array}$} & \multirow[t]{2}{*}{$\begin{array}{l}\text { No. } \\
\text { flowers }\end{array}$} & \multirow{2}{*}{$\begin{array}{l}\text { No. Bs } \\
0 \\
2\end{array}$} & \multirow{2}{*}{$\begin{array}{l}\begin{array}{l}\text { Got-3 } \\
\text { phenotype }\end{array} \\
11 \\
11\end{array}$} \\
\hline 1 & Females & & & & \\
\hline & Males & $\begin{array}{l}7 \\
7\end{array}$ & $\begin{array}{l}978 \\
985\end{array}$ & $\begin{array}{l}0 \\
0\end{array}$ & $\begin{array}{l}11 \\
12\end{array}$ \\
\hline 2 & Females & $\begin{array}{l}7 \\
7\end{array}$ & & $\begin{array}{l}0 \\
2\end{array}$ & $\begin{array}{l}11 \\
11\end{array}$ \\
\hline & Males & $\begin{array}{r}12 \\
3\end{array}$ & $\begin{array}{r}3121 \\
316\end{array}$ & $\begin{array}{l}0 \\
2\end{array}$ & $\begin{array}{l}12 \\
11\end{array}$ \\
\hline 3 & Females & $\begin{array}{l}7 \\
7\end{array}$ & & $\begin{array}{l}0 \\
2\end{array}$ & $\begin{array}{l}11 \\
11\end{array}$ \\
\hline & Males & $\begin{array}{r}3 \\
12\end{array}$ & $\begin{array}{r}620 \\
2948\end{array}$ & $\begin{array}{l}0 \\
2\end{array}$ & $\begin{array}{l}11 \\
12\end{array}$ \\
\hline 4 & Females & $\begin{array}{l}7 \\
7\end{array}$ & & $\begin{array}{l}0 \\
2\end{array}$ & $\begin{array}{l}11 \\
11\end{array}$ \\
\hline & Males & $\begin{array}{l}7 \\
7\end{array}$ & $\begin{array}{r}766 \\
1136\end{array}$ & $\begin{array}{l}0 \\
2\end{array}$ & $\begin{array}{l}11 \\
12\end{array}$ \\
\hline
\end{tabular}

number of flowers per plant was counted in the males (table 1).

In plot 1 all males were $0 \mathrm{Bs}$, and 50 per cent of them were 11 for Got-3 and 50 per cent 12 . Females were all 11 , but 50 per cent were $0 \mathrm{~B}$ and 50 per cent $2 \mathrm{~B}$. Therefore, this plot serves as a control of the equal viability of male gametes carrying alleles 1 or 2 on $0 \mathrm{~B}$ or $2 \mathrm{~B}$ females.

In plots 2 to 4 all females were homozygous 11 , but 50 per cent carried $0 \mathrm{~B}$ and 50 per cent $2 \mathrm{~B}$. Males were homozygous or heterozygous for Got3 , and had $\mathrm{OB}$ or $2 \mathrm{~B}$ in variable proportions in order to detect possible frequency-dependent deviations from random expectations.

The seeds of the offspring were analyzed to establish the GOT phenotype, the number of Bs, or both, by the techniques described above.

\section{RESULTS}

Table 2 shows the comparison between observed and expected Got-3 phenotypes in the offspring of both the $0 \mathrm{~B}$ and $2 \mathrm{~B}$ females.

It should first be noted that the proportion of males given in this table is different from that given in table 1 . This is because rye plants form a variable number of spikes per plant, and a variable number of flowers per spike. The total mass of pollen involved in fertilisation will be dependent on the number of flowers, rather than the number of plants. We therefore counted the number of flowers in males and the corresponding proportions of males were estimated.

Expected distribution of descendants were calculated as follows.

Plot 1: $3 / 4$ of male gametes carried allele 1 , while $1 / 4$ carried allele 2 . Since all females were $11,3 / 4$ of descendants will be 11 and $1 / 412$, on both the $0 \mathrm{~B}$ and the $2 \mathrm{~B}$ females. Observed offspring coincide almost exactly with expectations.

Plot 2: the male flower proportion was ten 12 to one 11 ; therefore, we expect $12 / 22$ of descendants to be 11 and $10 / 22$ to be 12 , on both the $0 \mathrm{~B}$ and the $2 \mathrm{~B}$ females. The difference between the observed and the expected offspring of $0 \mathrm{~B}$ females was significant. Following the same reasoning in plot 3 , in which the male proportion was five 12 to one 11 , we expect $7 / 12$ of descendants to be 11 and $5 / 12$ to be 12 . In plot 4 the expectation is $3 \cdot 5 / 5$ descendants 11 and $1 \cdot 5 / 512$.

In plots 3 and 4 the observed results did not differ significantly from the expected ones. It should also be noted that observed and expected distributions coincide almost exactly in the descendants of $2 \mathrm{~B}$ females. 
Table 2 Comparison between observed and expected offspring for Got-3 phenotypes assuming random fertilisation

\begin{tabular}{|c|c|c|c|c|c|c|c|c|c|c|}
\hline \multirow[b]{2}{*}{ Plot } & \multirow[t]{2}{*}{$\begin{array}{l}\text { Males } \\
\text { Propor. }\end{array}$} & \multirow[t]{2}{*}{ Bs } & \multirow[t]{2}{*}{ GOT } & & \multicolumn{3}{|c|}{$\begin{array}{l}\text { GOT phen. in offspring } \\
\text { of } 0 \mathrm{~B} \text { females }\end{array}$} & \multicolumn{3}{|c|}{$\begin{array}{l}\text { GOT phen. in offspring } \\
\text { of } 2 \mathrm{~B} \text { females }\end{array}$} \\
\hline & & & & & 11 & 12 & $x^{2}$ & 11 & 12 & $x^{2}$ \\
\hline 1 & $\begin{array}{l}1 \\
1\end{array}$ & $\begin{array}{l}0 \\
0\end{array}$ & $\begin{array}{l}11 \\
12\end{array}$ & $\begin{array}{l}\text { obs. } \\
\text { exp. }\end{array}$ & $\begin{array}{l}93 \\
92 \cdot 25\end{array}$ & $\begin{array}{l}30 \\
30 \cdot 75\end{array}$ & ns & $\begin{array}{l}94 \\
94 \cdot 5\end{array}$ & $\begin{array}{l}32 \\
31 \cdot 5\end{array}$ & ns \\
\hline 2 & $\begin{array}{r}10 \\
1\end{array}$ & $\begin{array}{l}0 \\
2\end{array}$ & $\begin{array}{l}12 \\
11\end{array}$ & $\begin{array}{l}\text { obs. } \\
\text { exp. }\end{array}$ & $\begin{array}{l}120 \\
105 \cdot 8\end{array}$ & $\begin{array}{l}74 \\
88 \cdot 2\end{array}$ & $*$ & $\begin{array}{l}115 \\
106 \cdot 2\end{array}$ & $\begin{array}{l}79 \\
87 \cdot 8\end{array}$ & ns \\
\hline 3 & $\begin{array}{l}1 \\
5\end{array}$ & $\begin{array}{l}0 \\
2\end{array}$ & $\begin{array}{l}11 \\
12\end{array}$ & $\begin{array}{l}\text { obs. } \\
\text { exp. }\end{array}$ & $\begin{array}{l}270 \\
259\end{array}$ & $\begin{array}{l}174 \\
185\end{array}$ & $\mathrm{~ns}$ & $\begin{array}{l}70 \\
71 \cdot 2\end{array}$ & $\begin{array}{l}52 \\
50 \cdot 8\end{array}$ & ns \\
\hline 4 & $\begin{array}{l}1 \\
1 \cdot 5\end{array}$ & $\begin{array}{l}0 \\
2\end{array}$ & $\begin{array}{l}11 \\
12\end{array}$ & $\begin{array}{l}\text { obs. } \\
\text { exp. }\end{array}$ & $\begin{array}{l}175 \\
168\end{array}$ & $\begin{array}{l}65 \\
72\end{array}$ & ns & $\begin{array}{l}88 \\
87 \cdot 5\end{array}$ & $\begin{array}{l}37 \\
37 \cdot 5\end{array}$ & ns \\
\hline
\end{tabular}

ns Non-significant.

* Significant at 0.05 level.

In addition to Got-3 phenotype, the number of B chromosomes was determined in a portion of the progeny of $0 \mathrm{~B}$ females in plots 2,3 and 4 . The observed and expected data are shown in table 3 .

For the calculation of the expected distributions two approaches can be used. The first one is based on the fact that $2 \mathrm{~B}$ plants produce 4 per cent of pollen grains without Bs. This frequency has been estimated by direct observation of first and second pollen grain mitosis (Kishikawa, 1965; Puertas et al., 1979). Let us take plot 2 as an example. In this plot there was a ratio of 10 males with $0 \mathrm{~B} 12$ to 1 male with $2 \mathrm{~B} 11$. $0 \mathrm{~B}$ males produce gametes $0 \mathrm{~B} 1$ and $0 \mathrm{~B} 2$ in a proportion of $10 / 22$ each. Therefore, the probability of obtaining $0 \mathrm{~B}$ 11 progeny is $10 / 22+0 \cdot 04(2 / 22)$, the probability of obtaining $0 \mathrm{~B} 12$ progeny is $10 / 22$, and the probability of 11 progeny with Bs is $0.96(2 / 22)$. The expectations for plots 3 and 4 were calculated in a similar manner.
Observed and expected values differed significantly in plots 2 and 3 , while in plot 4 the differences were nonsignificant. For the calculations of $\chi^{2}$ values the class $0 \mathrm{~B} 12$ in plots 3 and 4 was not considered since the expected number is very low.

The second approach was based on the estimation of $0 \mathrm{~B}$ pollen grains formed in $2 \mathrm{~B}$ plants that were involved in fertilisation. The frequencies of zygotes with or without Bs formed in $0 \mathrm{~B}$ females can be estimated from the data shown in table 3 . For example, in plot 3 six 12 plants with $0 \mathrm{~B}$ were obtained; therefore, $6 / 48=0 \cdot 125$ is the frequency of $0 \mathrm{~B}$ gametes involved in fertilisation, and so on. These estimations are shown in table 4 . They were used for calculating the expected progeny of each plot in a similar manner to that of the first approach, changing the value 0.04 by $0 \cdot 15,0 \cdot 125$, or $0 \cdot 214$, respectively. The deviations from random expectations were similar using both approaches.

Table 3 Isozyme phenotype and B chromosome number in descendants from $0 \mathrm{~B}$ females

Observed

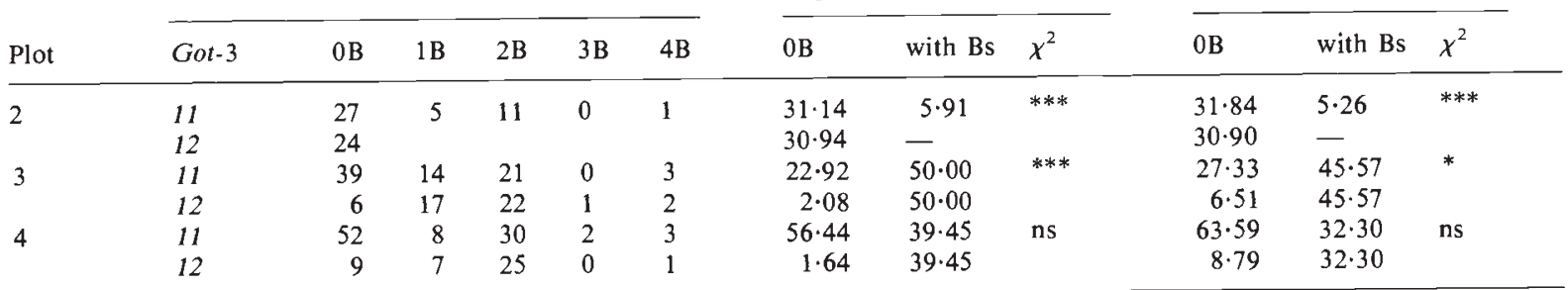

\footnotetext{
*** Significant at 0.001 level.

* Significant at 0.05 level.

ns Non-significant.
} 
Table 4 Estimated frequencies of zygotes formed in $0 \mathrm{~B}$ females which were fertilised by $2 \mathrm{~B}$ males

\begin{tabular}{lllll}
\hline \multirow{2}{*}{$\begin{array}{l}\text { No. of Bs } \\
\text { in pollen }\end{array}$} & 2 & 3 & 4 & $\begin{array}{c}\text { Pollen } \\
\text { formed* }\end{array}$ \\
\cline { 2 - 5 } & 2 & \multicolumn{4}{c}{ Plot } \\
\hline 0 & 0.15 & 0.125 & 0.214 & 0.04 \\
2 & 0.25 & 0.354 & 0.167 & 0.27 \\
3 & 0.55 & 0.458 & 0.595 & 0.64 \\
4 & 0.00 & 0.021 & 0.000 & 0.02 \\
& 0.05 & 0.042 & 0.024 & 0.03 \\
\hline
\end{tabular}

* Data from Kishikawa (1965) and Puertas et al. (1979).

\section{DISCUSSION}

In previous papers (Puertas and Lacadena, 1974; Puertas et al., 1986) we have demonstrated that rye $\mathrm{B}$ chromosomes are not transmitted at random. The different types of B-carrying pollen do not fertilise at the frequencies at which they are produced, but the involvement of pollen in fertilisation is also dependent on the frequency of plants with or without Bs in the population. The results reported in this work are in agreement with our previous data. We have used an isozyme marker locus (Got3 ) for the unambiguous identification of the pollen involved in fertilisation when various males (with or without Bs) were in competition.

The design of this experiment could be improved using only homozygous 11 and 22 plants, instead of 11 and 12. However, the frequency of 22 plants is low in this population; furthermore, the frequency of 22 plants with a given number of $\mathrm{Bs}$ is so low that the experiment would be unattainable.

Firstly, we have analyzed the progeny obtained with respect to Got-3 phenotypes (table 2). Plot 1 serves as a control for the Mendelian transmission of Got-3 alleles, since males did not carry Bs. Observed and expected offspring coincide both on $\mathrm{OB}$ and $2 \mathrm{~B}$ females. Therefore, it can be concluded that Got-3 is a good marker for our purpose and the deviations from random found in other plots can be attributed to the effects of the B chromosomes.

In plot 2 there were more male parents without Bs. In the offspring of $0 \mathrm{~B}$ females there are more 11 descendants observed than expected. This must be due to an excess of fertilisation by gametes carrying the allele 1 . Since male parents with Bs were 11 , this suggests that pollen formed in plants with Bs were preferentially involved in fertilisation.

In 2B females the difference between observed and expected offspring is not statistically sig- nificant, although it can be seen that there are also more 11 descendants than are expected.

In plot 3 the proportion of plants with and without Bs was contrary to plot 2: there were more male parents with Bs. The difference between the observed and expected offspring of the $0 \mathrm{~B}$ females is not significant, but it can be seen that there are more 11 plants. Since in this case males with Bs were 12 , it seems that pollen from plants with Bs took part in fertilisation less frequently than expected. This proposal will be considered below using the data in table 3.

The offspring collected on 2B females coincide almost exactly with expected, indicating that pollen from $0 \mathrm{~B}$ or $2 \mathrm{~B}$ male parents fertilised $2 \mathrm{~B}$ females at random.

In Plot 4 the same number of $0 \mathrm{~B}$ and $2 \mathrm{~B}$ male plants was sown, in order to study the effect of absence of competition. However, the variation in flower number resulted in a slightly greater proportion of male flowers with Bs. The results of this plot are similar to those of plot 3.

In addition to the Got-3 phenotype, the number of Bs was counted in a portion of the descendants of $0 \mathrm{~B}$ females in plots 2,3 and 4 . Table 3 shows the phenotype of plants with respect to both the number of Bs and the Got-3 locus. This double mark serves to determine more precisely the origin of pollen that participates in fertilisation. With the analysis of only the Got-3 locus we cannot know how many 11 plants were the progeny of $0 \mathrm{~B}$ or $2 \mathrm{~B}$ males, because allele 1 was present in both. However, by counting the number of Bs we are sure that all 11 plants with Bs must be formed by pollen from 2B males carrying allele 1 .

The observed and expected offspring shown in table 3 were significantly different in plots 2 and 3. These data demonstrate: firstly, the nonrandom fertilisation by pollen produced on $0 \mathrm{~B}$ or $2 \mathrm{~B}$ males. Secondly that, pollen from $2 \mathrm{~B}$ plants preferentially took part in fertilisation when there were few 2B males (plot 2) and, conversely, that pollen from $0 \mathrm{~B}$ plants preferentially took part in fertilisation when there were few 0B males (plot 3). For example: 5.91 plants with Bs were expected in plot 2 , but 17 were obtained; 100 plants with Bs were expected in plot 3 , but 80 were obtained.

In plot 4 in which the $0 \mathrm{~B}$ and the $2 \mathrm{~B}$ males were approximately equal in proportion, the observed progeny did not differ significantly from the expected, indicating that pollen from $0 \mathrm{~B}$ and 2B males participates in fertilisation at random when there is no competition.

A surprising result of this work is the difference between the frequencies of the different types of 
pollen grains formed in a $2 \mathrm{~B}$ plant, as estimated by direct observation of pollen mitoses, and the frequencies of pollen grains involved in fertilisation, as estimated from the observed progeny (table 4 ). The proportion of $0 \mathrm{~B}$ pollen formed is only 4 per cent, while it seems that it fertilises in a much higher proportion ( 12.5 to 21 per cent). This can occur if $0 \mathrm{~B}$ pollen is relatively more successful in fertilisation than pollen with $\mathrm{Bs}$, or $\mathrm{OB}$ zygotes are more viable, or both. However, this is not in contradiction with our previous conclusion, since pollen formed in 2B plants can be advantageous or disadvantageous depending on the frequency of plants with or without Bs in the population, while $0 \mathrm{~B}$ pollen grains or $0 \mathrm{~B}$ zygotes can be always more viable. Therefore, it seems that the competitive ability of pollen from $0 \mathrm{~B}$ or $2 \mathrm{~B}$ plants is sporophytically determined, irrespective of whether or not that pollen, or the zygotes, with or without Bs have different viabilities.

Our results strongly suggest that the competitive ability of pollen formed by $0 \mathrm{~B}$ or $2 \mathrm{~B}$ plants on $0 \mathrm{~B}$ females varies according to the frequency of plants with or without Bs in the population. It seems that when pollen grains land on a $0 \mathrm{~B}$ stigma the competitive ability of pollen of different parents is dependent on, and inversely related to their own proportion. This mechanism is favourable for B chromosomes because it tends to maintain them at a moderate frequency in a population (plants with many Bs have a very low fitness).

On the contrary, it also seems that on 2B females there is no competition between pollen from $0 \mathrm{~B}$ or $2 \mathrm{~B}$ plants, since the observed offspring coincides very well with expectations. If the main strategy of Bs is to maintain themselves, this absence of competition is also favorable for Bs since $2 \mathrm{~B}$ females transmit B chromosomes to the next generation irrespective of the male. However, this conclusion is not firmly established since we only have data of Got-3 and not of the number of $\mathrm{Bs}$ in descendants of $2 \mathrm{~B}$ females, because it is not possible to distinguish if their Bs come from male, female or both parents.

The main conclusion of this work is that pollen formed by $\mathrm{OB}$ and $2 \mathrm{~B}$ plants has a differential fertilising ability on $0 \mathrm{~B}$ females which is dependent on the frequency of $\mathrm{OB}$ or $2 \mathrm{~B}$ plants. By this mechanism the polymorphism for $\mathrm{B}$ chromosomes can be maintained in equilibrium by frequencydependent selection.

These properties make rye $\mathrm{B}$ chromosomes one of the best examples of selfish DNA: they do not have any known gene function, their effects are neutral or deleterious for carriers (see Jones and Rees, 1982 for a review), their transmission mechanisms tend to increase their number in spite of their deleterious effects, and finally their maintenance is frequency-dependent which is very appropriate for a parasitic type of behaviour.

Acknowledgements This work was supported by a grant from the Comisión Asesora de Investigación Científica y Técnica of Spain.

\section{REFERENCES}

DECKER, L. R. AND RAU, E. M. 1963. Multiple forms of glutamic-oxaloacetic transaminase in tissues. Proc. Soc. Exp. Biol. Med., 112, 144-149.

JONES, R. N. AND REES, H. 1982. B chromosomes. Academic Press, New York.

KISHIKAWA, H. 1965. Cytogenetic studies of B chromosomes in rye, Secale cereale in Japan. Agr. Bul. Saga Univ., 21, $1-81$.

HÅKANSON, A. 1948. Behaviour of accessory chromosomes in the embryo sac. Hereditas, 34, 35-39.

MÜNTZING, A. 1946. Cytological studies of extra fragment chromosomes in rye III. The mechanism of non-disjunction at the pollen mitosis. Hereditas, 32, 507-509.

MÜNTZING, A. 1963. Effects of accessory chromosomes in diploid and tetraploid rye. Hereditas, 49, 361-426.

PEREZ DE LA VEGA, M. AND AllARD, R. W. 1984. Mating system and genetic polymorphism in populations of Secale cereale and Secale vavilovii. Can. J. Genet. Cytol., 26, 308317.

PUERTAS, M. J., BAEZA, F. AND DE LA PENA, A. 1986. The transmission of B chromosomes in populations of Secale cereale and Secale vavilovii 1 . Offspring obtained from $0 \mathrm{~B}$ and 2B plants. Heredity, 57, 389-394.

PUERTAS, M. J., DIEZ, M. AND CARMONA, R. 1979. Rye B chromosome behaviour at first and second pollen mitosis and its relationship with anther maturity. Theor. Appl. Genet., 54, 65-68.

PUERTAS, M. J. AND LACADENA, J. R. 1974. The transmission of rye B chromosomes in natural pollination. Theor. Appl. Genet., 45, 195-204.

PUERTAS, M. J., ROMERA, F. AND DE LA PEÑA, A. 1985. Comparison of B chromosome effects on Secale cereale and Secale vavilovii. Heredity, 55, 229-234. 